\title{
O infundado entusiasmo com a participação privada em infraestrutura
}

\author{
The unfounded enthusiasm towards private \\ participation in infrastructure
}

EMILIO CHERNAVSKY*

\begin{abstract}
RESUMO: Apesar do entusiasmo disseminado com a participação privada na provisão de infraestrutura, as avaliações internacionais dos seus resultados são raras e inconclusivas. Os órgãos de auditoria são geralmente céticos quanto à sua superioridade, as instituições multilaterais têm sido cautelosas, e a população, crítica em muitos países. Mostro que esses resultados frustrantes estão associados aos lucros extraordinários e ao lento avanço da produtividade derivados da competição reduzida e da regulação ineficaz comuns no setor, e aponto razões que explicam essa situação. Argumento que o entusiasmo é infundado teórica e empiricamente, e se apoia na aceitação ideológica de duas hipóteses cruciais, altamente questionáveis.
\end{abstract}

PALAVRAS-CHAVE: Parcerias público-privadas; infraestrutura.

ABSTRACT: Despite the widespread enthusiasm for private participation in the provision of infrastructure, international assessments of its results are rare and inconclusive. Audit offices are generally skeptical of their superiority, multilateral institutions have been cautious, and the population is critical in many countries. I show these frustrating results are associated with the extraordinary profits and slow progress of productivity derived from reduced competition and ineffective regulation common in the sector, and point out reasons that explain this situation. I argue that enthusiasm is theoretically and empirically unfounded, and that on the ideological acceptance of two crucial, highly questionable hypotheses.

KEYWORDS: Public-private partnership; infrastructure.

JEL Classification: L32; H54.

\footnotetext{
* Doutor em Economia pela Faculdade de Economia e Administração da Universidade de São Paulo FEA-USP, São Paulo/SP, Brasil. E-mail: echernavsky@gmail.com. Orcid: https://orcid.org/0000-00024055-3502. Submetido: 20/Julho/2020: Aprovado; 31/Agosto/2020.
} 


\section{INTRODUÇÃO}

A melhoria da infraestrutura é central para o desenvolvimento de um país. Ela reduz os custos de produção e transporte, facilitando a integração do mercado interno e o intercâmbio com o exterior. Amplia com isso a concorrência e as escalas de operação e, ao induzir o investimento e elevar a produtividade, acelera o crescimento econômico. Também expande a oferta e a qualidade dos serviços públicos, aumentando diretamente o bem-estar da população. Ainda, os investimentos a ela associados possuem poderosos efeitos indutores que contribuem para expandir o nível de atividade econômica.

A despeito dessa importância, desde os 1980s os investimentos em infraestrutura no Brasil, historicamente custeados e executados pelo governo, têm geralmente permanecido em níveis muito abaixo dos registrados em outros países em desenvolvimento e no próprio país nas décadas anteriores, e mesmo abaixo dos necessários para compensar a depreciação dos ativos existentes (Frischtak e Mourão, 2018). Nesse contexto, disseminou-se progressivamente no debate público nacional a defesa do setor privado na provisão de infraestrutura. Nessa defesa, vocalizada por representantes eleitos, burocratas governamentais e especialistas na academia, associações e consultorias e outros, o setor privado aportaria não só os recursos financeiros requeridos para retomar os investimentos que o Estado já não mais disporia, como traria inovações tecnológicas e gerenciais, ganhos de escopo, maior capacidade de gerenciar certos riscos e maior eficiência na execução dos projetos.

Com o ambiente político favorável, desde os 1990s importantes mudanças institucionais foram promovidas no Brasil para tornar a participação privada em infraestrutura legalmente viável e atrativa para possíveis interessados. As mudanças abrangem alterações na legislação, inclusive na Constituição Federal ${ }^{1}$, a criação de uma custosa estrutura regulatória estatal, bem como decisões administrativas e orçamentárias ${ }^{2}$ de sucessivos governos nos âmbitos federal e estadual. Graças a tais mudanças, a infraestrutura no país foi sendo gradativamente assumida pelo setor privado. Isso se deu, contudo, de forma muito heterogênea e majoritariamente por meio da aquisição do direito de exploração de ativos existentes operados por entidades públicas, sendo poucos os casos em que o setor privado avançou em projetos genuinamente novos. Essa constatação não parece, todavia, abalar a confiança no potencial do setor privado; ao contrário, seu protagonismo tem sido cada vez mais reivindicado por analistas, associações empresariais ${ }^{3}$ e técnicos e dirigentes de go-

\footnotetext{
${ }^{1}$ Destacam-se neste sentido as Emendas Constitucionais nos 5, 6 e 8 de 1995, as leis das concessões (8.987/1995) e das parcerias público-privadas - PPPs (11.079/2004) e alterações posteriores, a lei do Programa de Parcerias de Investimentos - PPI (13.334/2016), e as leis de criação das agências reguladoras.

${ }^{2}$ As decisões envolvem, em particular, a privatização de empresas estatais e a redução do orçamento e das atribuições daquelas que permaneceram nas mãos do governo.
}

${ }^{3}$ Ver, por exemplo, CNI (2017). 
vernos oriundos de praticamente todo o espectro político. A ideia de que a entrada maciça do setor privado não só é possível, mas também a melhor quando não a única alternativa para implantar um extenso programa de investimentos que transforme a infraestrutura do país, se tornou assim quase consensual e, desde o anúncio do Programa de Investimentos em Logística - PIL em 2012, inteiramente apoiado em investimentos privados, embasa a política do Governo Federal na área sem ser desafiada. Ao contrário, tem sido evocada com entusiasmo pelos sucessivos governos.

Este trabalho se propõe a investigar se esse entusiasmo é teórica e empiricamente justificável. Com esse objetivo, se divide em mais sete seções além desta introdução. Na próxima, descreve-se brevemente o avanço privado na infraestrutura desde o início dos 1990s. A terceira seção aponta a falta de evidências empíricas robustas em favor da provisão privada bem como os crescentes questionamentos a seus resultados, e a quarta discute os problemas dos argumentos mais usados para defendê-la. A quinta seção mostra a alta lucratividade e o lento avanço da produtividade que caracterizam o setor de infraestrutura, enquanto a sexta discute a competição reduzida e a regulação ineficaz que geralmente explicam essa situação. A sétima seção aponta certos custos que tendem a ser maiores na provisão privada e que, em conjunto com os lucros elevados e o avanço lento da produtividade, pioram seu custo-benefício. Finalmente, a oitava seção mostra que o entusiasmo em torno à expansão privada na infraestrutura não obstante as objeções teóricas e empíricas exige a aceitação ideológica de duas hipóteses cruciais altamente questionáveis.

\section{O AVANÇO DO SETOR PRIVADO NA INFRAESTRUTURA}

A participação privada na provisão da infraestrutura se dá por meio de uma ampla variedade de arranjos contratuais que caracterizam uma parceria público-privada - PPP. Na definição genérica do Banco Mundial, uma PPP é*

"um contrato de longo prazo entre um parceiro privado e uma entidade governamental para a provisão de um ativo público ou serviço, no qual o parceiro privado detém parcela significativa do risco e da responsabilidade gerencial e a remuneração está ligada ao desempenho"4.

Esta definição inclui notadamente as atividades de desenho, financiamento, construção e manutenção dos projetos de infraestrutura, bem como a operação dos serviços associados ${ }^{5}$, e abrange os tipos de contratos que no Brasil são regidos

\footnotetext{
4 What is a PPP: Defining “Public-Private Partnership”. Disponível em https://pppknowledgelab.org/ guide/sections/3-what-is-a-ppp-defining-public-private-partnership.

* Esta e as demais citações neste trabalho foram traduzidas do original em inglês pelo autor.

${ }^{5}$ Nem todas as atividades indicadas estão necessariamente presentes em toda PPP.
} 
pelas leis das concessões e das PPPs $^{6}$ e por modalidades da lei geral de contratações. Embora na contratação tradicional o governo também adquira produtos e serviços do setor privado, o que diferencia as PPPs é que nelas o parceiro privado é o responsável pelo financiamento do projeto (mesmo que utilize recursos públicos), assume o controle ou a propriedade dos ativos por longos períodos, e fornece um pacote geralmente amplo de produtos e serviços. Até o início dos 1990s, praticamente não existiam PPPs no país. Contudo, a partir de meados da década elas cresceram rapidamente impulsionadas pelas privatizações principalmente nos setores de energia elétrica e telefonia. Após esse ímpeto inicial, o movimento perdeu força no início dos 2000s, não só porque o potencial das privatizações é naturalmente limitado aos ativos existentes, mas também em razão das crises financeiras no final dos 1990s que elevaram a aversão ao risco em países em desenvolvimento, e do estouro da bolha pontocom e a desaceleração econômica global que reduziram os preços nos leilões (Ettinger et al.., 2005). Assim, embora contratos continuassem a ser assinados, os investimentos caíram fortemente e, como mostra o Gráfico 1, somente voltaram a crescer na segunda metade da década com a expansão das concessões em energia e transportes em um contexto de otimismo com o país e de grande liquidez global.

Gráfico 1: Número de contratos assinados e compromisso de investimentos em projetos de infraestrutura com participação privada no Brasil

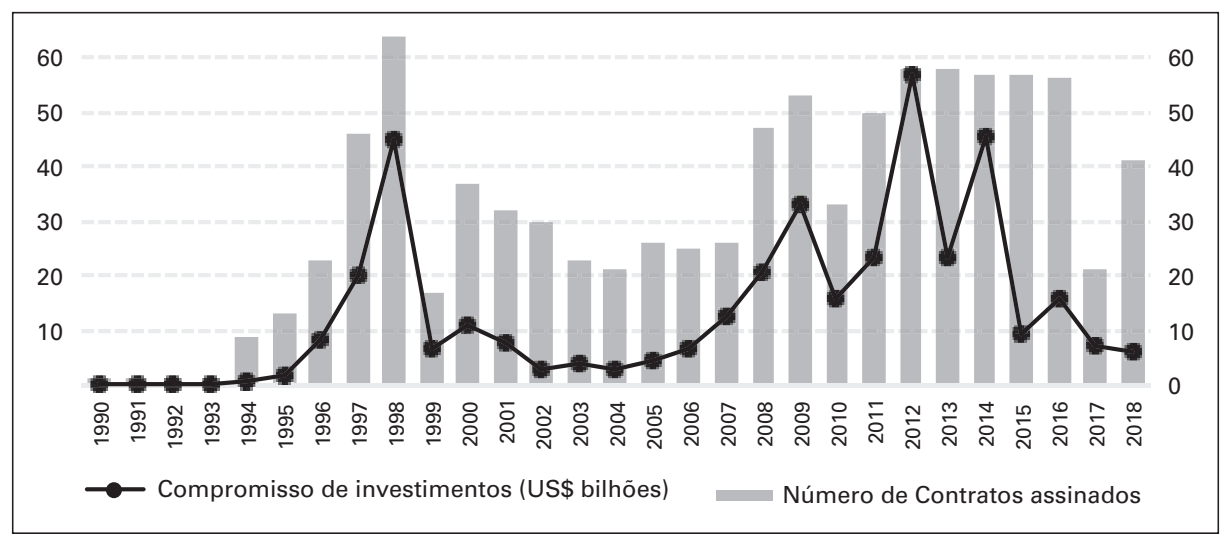

Fonte: World Bank ppi database.

Elaboração própria.

\footnotetext{
${ }^{6}$ No Brasil, a que é conhecida como lei das PPPs regulamenta dois tipos de concessão: a patrocinada, onde o parceiro privado, além da tarifa paga pelos usuários como nos contratos regidos pela lei das concessões, é remunerado por contraprestação do parceiro público; e a administrativa, em que o governo é o usuário direto ou indireto do objeto do contrato e o remunera integralmente. Neste trabalho, as PPPs são entendidas em seu sentido amplo, englobando todas as concessões e outras modalidades de parceria.
} 
$\mathrm{O}$ avanço dos investimentos privados em infraestrutura seguiu padrão semelhante em outros países em desenvolvimento, com uma primeira onda impulsionada pelo surto de privatizações na segunda metade dos 1990s e uma segunda alimentada pelo influxo de capitais externos a partir de meados dos 2000s. Tal avanço recebeu o importante apoio de uma rede de organismos multilaterais - em especial o Banco Mundial7 (World Bank, 1994, 2003, 2013) -, governos nacionais, consultorias especializadas na estruturação técnica, legal e financeira de projetos, e empresas dedicadas à sua execução. Esse apoio assume a forma de visitas técnicas, publicação de estudos e organização de eventos e, no caso dos bancos, da imposição da condição de que os projetos por eles financiados sejam executados por PPPs (Hall, 2015). Ele tem motivado não apenas as decisões de contratar projetos usando o arranjo, mas também as de realizar reformas institucionais que alteram a forma de atuação do Estado na infraestrutura e que são necessárias para viabilizar a expansão da participação privada ${ }^{8}$. Essas reformas ocorreram e continuam a ocorrer (World Bank, 2018) de forma generalizada nos países em desenvolvimento que, por exemplo, em sua grande maioria criou leis específicas, separadas das regras gerais do setor público, para contratar PPPs, e instituiu uma unidade do governo a elas dedicada9

Reformas institucionais também ocorreram nos países desenvolvidos, embora não da mesma forma. Diferente daqueles, na maioria dos membros da OCDE a contratação das PPPs se manteve dentro das leis gerais de contratações públicas e, embora a grande expansão privada também tenha começado em meados dos 1990s, não recuou no início dos 2000s e continuou até 2008. Naquele ano, todavia, o movimento se inverteu sob o impacto da crise financeira global.

\section{DÚVIDAS E QUESTIONAMENTOS}

A crise, além de elevar fortemente os custos de captação privados para os projetos (Abadie, 2008), praticamente secou os mercados de capitais e crédito de longo prazo cruciais para viabilizar as PPPs. Além disso, elevou o risco cambial e reduziu a demanda pelos serviços - e, com isso, o fluxo de caixa e a rentabilidade dos empreendimentos em execução e previstos. A resposta imediata foi o adiamen-

\footnotetext{
${ }^{7}$ Em sua estratégia atual, o Banco Mundial inclusive explicita a orientação de "promover crescentemente as parceiras público-privadas" (World Bank, 2013, p.2), e "aprovou 407 empréstimos com um componente de PPP entre 2002 e 2016, [e] tem feito contribuições significativas para o desenvolvimento regulatório e institucional das PPPs" (https://www.worldbank.org/en/topic/publicprivatepartnerships/ overview\#3).

${ }^{8}$ Desde 1999 a Public-Private Infrastructure Advisory Facility - PPIAF abrigada no Banco Mundial provê assistência técnica para fortalecer as bases políticas, regulatórias e institucionais para viabilizar o investimento privado em infraestrutura em países em desenvolvimento (https://ppiaf.org/ppiafcelebrating-20-years).

${ }^{9}$ Estas foram criadas inclusive em países com institucionalidade notadamente frágil como o Afeganistão.
} 
to de grande número de projetos em todo o mundo (Burger et al., 2009). Em muitos casos, em especial nos países desenvolvidos, por tempo indeterminado.

De fato, ao contrário dos países em desenvolvimento, onde dois anos após o choque global a expansão já era retomada no contexto de abundância de liquidez nos mercados financeiros globais (Bayliss e Van Waeyenberge, 2018), em muitos países desenvolvidos, em especial na Europa, o número de novas PPPs seguiu caindo no ambiente de austeridade fiscal generalizado na região na esteira da crise. Isso porque esta, ao reduzir as receitas do governo e drenar volumosos recursos para o resgate de instituições financeiras insolventes, afetou pesadamente as finanças públicas de vários países, reduzindo recursos e interrompendo projetos que, previa-se até então, receberiam aportes dos governos. Mas além de impor restrições orçamentárias a novas ações, os problemas fiscais explicitaram os custos elevados e rígidos das PPPs, absorvendo recursos públicos que haviam se tornado então claramente escassos. Além disso, mostraram que ao invés de, como prometido, ajudar a melhorar a situação fiscal, a adoção das PPPs a piorava. De fato, os países que mais recorreram às parcerias - Chipre, Grécia, Irlanda, Portugal e Espanha, além do Reino Unido, pioneiro no avanço privado na infraestrutura que responde até hoje por mais da metade do total de projetos na região - foram justamente os mais afetados pela crise. Isso levou, inclusive, os pacotes de resgate financeiro firmados com a troika ${ }^{10}$ a se referirem explicitamente à contribuição das parcerias aos problemas fiscais e a exigirem sua auditoria e renegociação, além de congelarem novos projetos (Hall, 2015).

Com a visibilidade dos custos e dos compromissos associados às PPPs obrigando os governos a cortar gastos em outras áreas ou a elevar tributos para manter as transferências ao parceiro privado, o quase consenso no final do século XX em torno à superioridade do mercado passou a ser questionado (Flinders, 2010). Tornaram-se comuns as dúvidas quanto ao seu desempenho na provisão da infraestrutura em termos da qualidade, disponibilidade e, especialmente, custos aos usuários e à sociedade em geral, e cresceu o interesse pelas avaliações dos seus resultados. Frustrando as expectativas, estas têm se mostrado menos numerosas e conclusivas e, quando o são, menos favoráveis às PPPs (Hodge e Greve, 2007 e 2017; Boardman et al., 2016) do que se poderia esperar diante do seu grande avanço nas últimas décadas e do entusiasmo que seguem despertando em organismos multilaterais, empresas e governos e no imaginário popular ao redor do mundo. Ainda, as que mostram resultados positivos comumente possuem problemas metodológicos importantes que limitam sua confiabilidade. Em especial, comparam custos reais da contratação tradicional com projeções ex-ante de custo das PPPs, em vez de custos reais ex-post; são estatisticamente pouco rigorosas e usam contrafactuais de contratação tradicional vagos (Hodge, 2010); aplicam taxas de desconto muito altas (Boardman e Vining, 2010) que penalizam a contratação tradicional, tida como concentrada no momento da aquisição como se o governo não

\footnotetext{
${ }^{10}$ Grupo formado pelo FMI, Comissão Europeia e Banco Central Europeu para analisar as contas públicas e negociar com os países europeus que solicitaram resgate financeiro no início dos 2010s.
} 
pudesse se endividar, enquanto o gasto com as PPPs é diferido; avaliam prazos a partir da assinatura dos contratos, ignorando o período de preparação dos projetos em geral muito mais longo nas PPPs (Pollock et al., 2007); limitam seu escopo a aspectos escolhidos dos projetos (tipicamente, qualidade e/ou prazo de compleição) ignorando os demais, em especial os custos e possíveis externalidades; e atribuem melhorias nos serviços oriundas de mudanças tecnológicas à PPP, como se a contratação tradicional não pudesse também adotá-las.

Em boa medida, esses problemas são produto do ambiente dominante nas últimas décadas, em que o recurso ao setor privado com frequência se tornou a única opção para governos que pretendessem investir em meio à permanente restrição orçamentária ${ }^{11}$, e o objetivo central das avaliações muitas vezes passou a ser o de justificar decisões já tomadas de adotar ou expandir a participação privada ${ }^{12}$.

A escassez de avaliações robustas dos projetos de PPPs é identificada pelos órgãos oficiais de auditoria, geralmente ligados aos Parlamentos e com graus variados de independência. Como apontam Boers et al., após revisar 48 relatórios de 21 desses órgãos em 13 países:

"ainda não há evidência de que projetos de desenho, construção, financiamento, manutenção e operação [privados] representam a forma mais eficiente de contratação governamental. Não surpreendentemente, muitos órgãos são críticos das premissas feitas sobre os projetos.” (2013, p.471).

Recente relatório da Corte Europeia de Auditores sobre o assunto revela cautela no próprio título: "Parcerias público-privadas na União Europeia: deficiências disseminadas e benefícios limitados" (ECA, 2018). Mesmo no Brasil, apesar do otimismo largamente reinante em relação à participação privada na infraestrutura, o Tribunal de Contas da União também levanta dúvidas quanto ao caso geralmente considerado bem-sucedido das concessões no setor rodoviário:

“O programa de concessões rodoviárias já está em curso há cerca de 25 anos, e tem sido visto como esperança para a solução dos problemas nacionais de infraestrutura de transporte, porém sem uma avaliação que venha comprovar ser esta a alternativa mais vantajosa ao interesse público. A ausência de dados e informações padronizadas impede uma avaliação acurada sobre as melhorias que as concessões de rodovias trouxeram para os usuários" (TCU, 2019, p.35).

\footnotetext{
${ }^{11}$ Por exemplo, relatório do Comitê do Tesouro do Parlamento Britânico aponta que no Reino Unido "Por tempo demais a provisão privada tem sido a unica solução disponível em alguns setores aos quais não foi alocado orçamento adequado para suas necessidades de investimento. [...] Se a provisão privada é a única opção [...] ela será usada mesmo se seu custo-benefício não for o melhor" (Parliament, 2011a, par.69).

${ }^{12}$ Não estranha, por isso, a afirmação de que "justificativas do governo para usar a provisão privada não estão baseadas em análise robusta, mas em comparações mal fundamentadas e hipóteses inválidas” (Parliament, 2011b, summary).
} 
Em particular, a britânica National Audit Office - NAO mostra pouco entusiasmo quanto aos resultados da larga experiência do Reino Unido com PPPs ao por exemplo afirmar, no sítio na internet que introduz as lições aprendidas, que

"não tem sido feita uma avaliação sistemática do value for money dos projetos operacionais por parte dos órgãos [do governo]. Há, portanto, dados insuficientes para demonstrar se o uso de recursos privados conduziu a um VFM melhor ou pior do que outras formas de contratação"13.

Esse tipo de conclusão é recorrente nos relatórios produzidos pelo órgão. O de 2009, por exemplo, após analisar mais de 100 projetos, apontava que

"frequentemente não conseguem demonstrar adequadamente que a iniciativa privada traz o melhor value for money [e que] se coloca peso demais em avaliações de risco que podem ser facilmente ajustadas para mostrar que a iniciativa privada é mais barata" (NAO, 2009, p.8).

Afirmações similares questionando as hipóteses que subsidiam a opção pelas PPPs bem como os resultados do arranjo marcam os relatórios seguintes (NAO, 2011 e 2013), inclusive o mais recente, que informava não haver "dados disponiveis sobre os benefícios do financiamento privado" e que "seu desempenho geral não havia sido quantificado" (NAO, 2018, p.18) ${ }^{14}$.

O critério central para avaliar o desempenho das PPPs amplamente utilizado no Reino Unido e na literatura internacional é o Value for Money - FVM ${ }^{15}$. Numa contratação pública, o VFM busca capturar o gasto do governo levando em conta não apenas seu volume, mas também sua eficiência (relação desse gasto com os bens e/ou serviços adquiridos) e efetividade (relação entre os resultados efetivos e os pretendidos), considerando todo o ciclo de vida da contratação assim como os riscos envolvidos. Neste trabalho optou-se por usar o termo custo-benefício, conhecido no Brasil e próximo ao VFM.

Além dos órgãos de auditoria, nos últimos anos também os organismos multilaterais têm se mostrado mais comedidos em relação ao desempenho das PPPs. Ao contrário do entusiasmo quase incondicional das décadas anteriores, suas publicações têm intercalado mensagens de incentivo com alertas sobre as condições que as instituições do país, as capacidades estatais e os projetos devem atender para que os benefícios prometidos possam ser alcançados. Nesse sentido, por exemplo, a OCDE aponta que

\footnotetext{
13 Ver https://www.nao.org.uk/report/lessons-from-pfi-and-other-projects/.

${ }^{14}$ Também no Parlamento Britânico observações ásperas nesse sentido têm sido feitas: "O uso da provisão privada tem se baseado em comparações inadequadas com a contratação convencional que não têm sido suficientemente questionadas" (Parliament, 2011b, par.1.)

${ }^{15}$ Ver https://www.nao.org.uk/successful-commissioning/general-principles/value-for-money/assessingvalue-for-money/.
} 
"pode ser difícil obter melhor custo-benefício das PPPs se as agências do governo não estiverem equipadas para gerenciá-las efetivamente", [e elas podem ser] "potencialmente arriscadas para a sustentabilidade fiscal" 16. [Ainda,] "há um número de condições que devem ser cumpridas para que uma PPP seja bem-sucedida” (OECD, 2012, p.18).

Já o FMI indica que "nem todos os projetos de investimento podem ser efetivamente entregues usando PPPs", e que a "evidência sobre se as PPPs podem fornecer infraestrutura de forma mais eficiente que a contratação pública tradicional é inconclusiva" (IMF, 2015, p.11).

Mesmo o Banco Mundial tem sido mais ponderado, por exemplo, ao afirmar no sítio na internet de introdução às PPPs que elas podem trazer maior eficiência e sustentabilidade na provisão de serviços públicos desde que sejam "bem desenhadas e implantadas em um ambiente regulatório balanceado". Aponta também que "muito trabalho é necessário para tornar os projetos 'prontos para o investidor' e para desenvolver marcos inovadores para alavancar o investimento privado" 17 .

O pouco entusiasmo dos órgãos oficiais de auditoria e a maior cautela das agências multilaterais acompanham a piora da percepção sobre o avanço privado na prestação de serviços públicos na população. Isso porque enquanto em muitos casos esse avanço não propiciou a esperada melhora da qualidade, com frequência levou a maiores tarifas. Por exemplo, Alexandersson e Hulten (2009) mostram que muitas PPPs no setor de transporte em países europeus criaram sistemas ineficientes, subutilizados e deficitários. Dee (2010) apontou que nos países da APEC os preços dos operadores de energia elétrica totalmente privados eram $23 \%$ superiores aos totalmente públicos, enquanto Fiorio e Florio (2013) chegaram a resultados semelhantes em 15 países europeus. No setor de saneamento, estudo recente (Labour, 2018) indicou que nos 25 anos desde sua privatização as contas aos consumidores cresceram 40\%. Chong et al., (2006) mostraram que, na França, nas cidades em que a água é distribuída por empresas privadas seu preço é $17 \%$ maior que naquelas em que as prefeituras o fazem diretamente. No Brasil, também no saneamento, recente relatório produzido pelo próprio setor privado para defender sua atuação mostra que as tarifas médias praticadas têm sido superiores às do setor público (AbconSindcon, 2018). No mesmo sentido, o gráfico 2 aponta o aumento das tarifas de telefonia, eletricidade e rodovias em ritmo por vezes muito superior ao do índice de preços ao consumidor nos anos que se seguiram aos processos total (telefonia) e parcial de privatização no país nos 1990s.

Tais situações têm gerado protestos frequentes e contribuíram, em ao menos 924 casos em todo o mundo entre 2000 e 2019, para reverter privatizações em vários setores (Kishimoto et al., 2019). Exemplo especialmente significativo da percepção negativa do desempenho privado é dado pelo Reino Unido, onde recente pesquisa de opinião largamente repercutida mostrou que mais de três quartos

\footnotetext{
${ }^{16}$ Ver https://www.oecd.org/governance/oecd-recommendation-public-privatepartnerships.htm.

17 Ver https://www.worldbank.org/en/topic/publicprivatepartnerships/overview.
} 


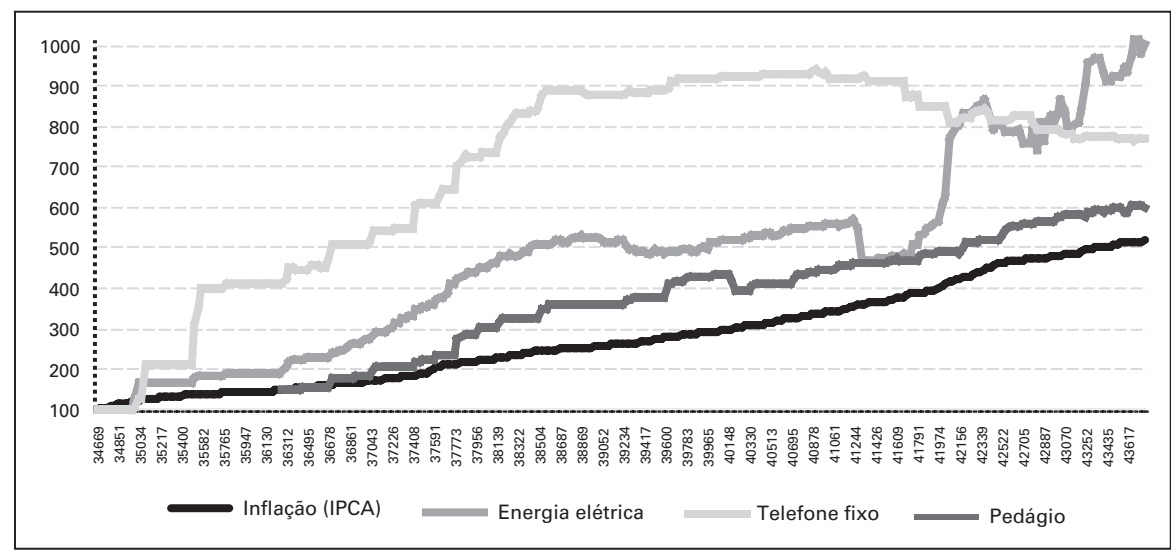

Fonte: IBGE. Elaboração própria.

da população acreditava que os serviços de transporte ferroviário, gás, eletricidade e saneamento deveriam estar nas mãos do governo (Elliott e Kanagasooriam, 2017). Assim, não surpreende que a proposta de estatização desses serviços desfrute de grande popularidade hoje no país, levando o opositor partido trabalhista a mudar seu posicionamento das últimas décadas e a defendê-la abertamente, e o governo conservador, mesmo sendo o responsável pela grande onda de privatizações nos 1980s e pela introdução das PPPs no início dos 1990s, a decidir, em 2018, não mais utilizá-las em novos projetos de infraestrutura ${ }^{18}$.

Os resultados duvidosos na base dos questionamentos à participação privada na infraestrutura após mais de duas décadas de expansão em todo o mundo podem frustrar quem esperaria que o aparente consenso favorável nos meios empresariais, políticos e jornalísticos no Brasil estivesse apoiado em bases empíricas sólidas. Entretanto, como se mostrará nas próximas seções, esses resultados não surpreendem se examinamos algumas características centrais das PPPs.

\section{FRUSTRAÇÃO PREVISÍVEL}

A participação privada na infraestrutura é geralmente justificada com base em dois argumentos principais. O primeiro alega que o Estado não mais disporia dos recursos financeiros necessários aos investimentos, e que sem os recursos privados eles não ocorreriam. A participação privada seria, portanto, não uma escolha, mas uma imposição da realidade. Já o segundo a coloca como a opção que propiciaria o melhor custo-benefício na provisão de infraestrutura. Como veremos, ambos os argumentos possuem sérios problemas que ajudam a explicar as frequentes frustrações com os resultados alcançados.

\footnotetext{
${ }^{18}$ Ver https://commonslibrary.parliament.uk/parliament-and-elections/government/goodbye-pfi/.
} 


\section{Falta de recursos: a participação privada como necessidade}

Para que o primeiro argumento acima seja válido, ou seja, para que a participação privada seja indispensável para os investimentos em infraestrutura, é preciso não somente que o Estado não consiga direcionar a eles parte da arrecadação de tributos, mas, também, que não consiga se endividar ou que enfrente dificuldades maiores que o setor privado para isso, incorrendo em taxas de juros mais altas e prazos médios mais curtos. No entanto, o que geralmente ocorre na realidade é justamente o contrário: os governos de países que, como o Brasil, emitem a própria moeda em que (a maior parte de) suas dívidas devem ser honradas e na qual os pagamentos dentro do país, em particular os tributos, são feitos, desfrutam das melhores condições para se endividar nessa moeda dentro de sua jurisdição ${ }^{19}$. Assim, o apelo ao setor privado para investir em infraestrutura devido à falta de recursos do Estado geralmente não faz sentido. Apenas em países que não emitem a própria moeda ou, se a emitem, somente em situações singulares em que a dívida pública se torna arriscada demais em meio a episódios de hiperinflação e ruptura do padrão monetário ou de default da dívida externa, é que o Estado de fato não consegue se financiar e o aporte privado se tornaria efetivamente indispensável. Contudo, na incerteza que caracteriza tais situações, dificilmente o setor privado investiria.

Não surpreende por isso que apesar de ter sido e continuar a ser frequentemente evocado, o argumento da falta de recursos tenha escassa sustentação empírica e que se acumulem, ao contrário, evidências que o contradizem. No Brasil, por exemplo, boa parte dos investimentos das empresas privatizadas nos 1990s, assim como a ampla maioria dos investimentos realizados por PPPs durante o último ciclo de expansão entre 2007 e 2014, foi financiada não com recursos privados, mas, sim, emprestados por bancos públicos, notadamente o BNDES. Ou seja, nos dois momentos em que o setor privado mais avançou na provisão de infraestrutura no Brasil o Estado não carecia de recursos, que existiam e foram direcionados para elevar a atratividade dos investimentos e viabilizar aquele avanço.

Da mesma forma, apenas um ano após contratar em 2007 o segundo maior número de PPPs da história, o governo do Reino Unido lançou em meio ao aprofundamento da crise financeira global em 2008 um pacote de resgate aos bancos que disponibilizou rapidamente cerca de um terço do PIB $^{20}$. Ou seja, tampouco neste caso a participação privada na infraestrutura era motivada pela falta de recursos do Estado.

Um fator relacionado, entretanto, ajuda a explicar essa participação. Ainda que tenha acesso ao crédito em condições favoráveis e, desse ponto de vista, não enfrente óbices para investir, o Estado está sujeito a restrições autoimpostas na

\footnotetext{
${ }^{19}$ Deve-se apontar que entes subnacionais e Estados nacionais que não emitem a própria moeda, como os que fazem parte da União Europeia, não desfrutam necessariamente das melhores condições de financiamento em sua jurisdição, o que pode justificar o apelo ao investimento privado.

20 Ver https://www.telegraph.co.uk/finance/financialcrisis/3157728/Gordon-Brown-hails-500-billionbank-rescue-plan.html.
} 
forma de limites definidos na legislação ou constrangimentos políticos ao endividamento e ao gasto que dificultam ou mesmo impedem o investimento público. Este, ao ser contabilizado imediatamente pelo seu montante total, afeta de forma direta as contas do governo, enquanto seu investimento numa PPP é amortizado ao longo de todo o período do contrato e afeta de forma apenas marginal o gasto público no exercício em que é realizado. Com isso, apesar de comprometer o governo com um fluxo de pagamentos ao parceiro privado por um longo período, esse investimento não impacta a dívida pública, permanecendo fora do balanço do Estado. Essa diferença, apoiada em convenções puramente arbitrárias sobre a maneira de contabilizar os investimentos na maioria dos países, inclusive no Brasil, permite às PPPs ajudarem os governos a contornar as regras fiscais às quais eles decidem se sujeitar, e tem se mostrado um poderoso incentivo à sua adoção. Este tem se sobreposto a quaisquer outras considerações (Boardmand et al., 2016; Shaoul et al., 2012; IMF, 2015), em particular à análise do value for money da contratação (NAO, 2009 e 2018), e levado a escolhas que por esse critério seriam equivocadas uma vez que, ao invés de melhorá-lo, apenas transferem custos e riscos elevados para o futuro (Araújo e Sutherland, 2010; Jin e Rial, 2016).

\section{Melhor custo-benefício: a participação privada como escolha}

O segundo argumento mais usado para justificar a provisão privada de infraestrutura defende que, se não a única possível, essa seria a escolha que propiciaria as contratações com o melhor custo-benefício e, portanto, a que melhor atenderia ao interesse público. Isso se refletiria na maior qualidade da infraestrutura e dos serviços, em menores tarifas cobradas dos usuários, menores pagamentos do governo ao parceiro privado - contraprestações - pela disponibilização da infraestrutura, maiores pagamentos do parceiro privado ao governo pelo direito de operá-la - outorgas -, ou numa combinação dos resultados. Estes seriam fruto da redução de custos propiciada pela maior produtividade do setor privado, derivada do uso de processos mais ágeis e econômicos na execução dos projetos e operação dos serviços, da incorporação mais rápida de inovações tecnológicas e gerenciais, dos ganhos de escopo com o fornecimento conjunto de produtos e serviços, e da maior capacidade de gerenciar riscos. Contudo, para que essa redução de custos efetivamente melhore o custo-benefício da contratação, favorecendo as finanças públicas e/ou os usuários dos serviços, ela deve ser maior, em valores absolutos, que a soma dos lucros apropriados pelo setor privado, que simplesmente não existem na provisão direta de infraestrutura pelo governo, e do aumento do custo de certos itens (principalmente de capital e transação) geralmente verificado pela provisão privada. Ou seja, a melhora do custo-benefício requer que a seguinte condição seja obrigatoriamente atendida:

\section{Condição para melhor custo-benefício da provisão privada de infraestrutura pública}

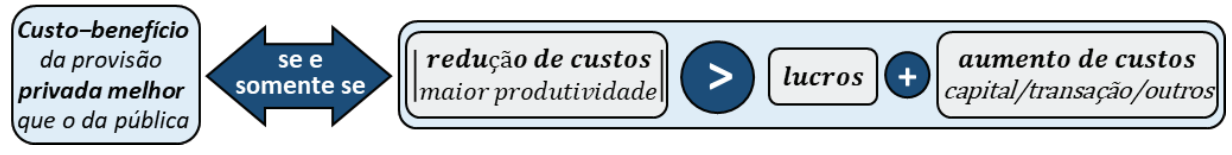


Quando isso não ocorre, a participação privada leva o custo-benefício da infraestrutura a piorar, ao invés de melhorar. Veremos nas próximas seções porque, ao contrário do que o entusiasmo existente em torno às PPPs sugere, esse resultado negativo é o mais provável na maioria das situações reais.

\section{LUCROS EXTRAORDINÁRIOS E AVANÇO LENTO DA PRODUTIVIDADE}

O atendimento da condição citada requer que os lucros auferidos sejam os menores possíveis e a redução de custos propiciada pelo aumento da produtividade seja a maior possível. Todavia, é o contrário o que se verifica na realidade na maior parte dos casos. Com efeito, apesar da grande heterogeneidade entre períodos, setores e países e, dentro de cada país, entre distintas empresas, a lucratividade daquelas que atuam no setor de infraestrutura com frequência é mais elevada que a dos demais setores, como mostram os Gráficos 3 e 4 para os casos do Brasil e dos EUA.

Gráfico 3: Margem operacional* por setor, Brasil (média 2014-2018) - \%

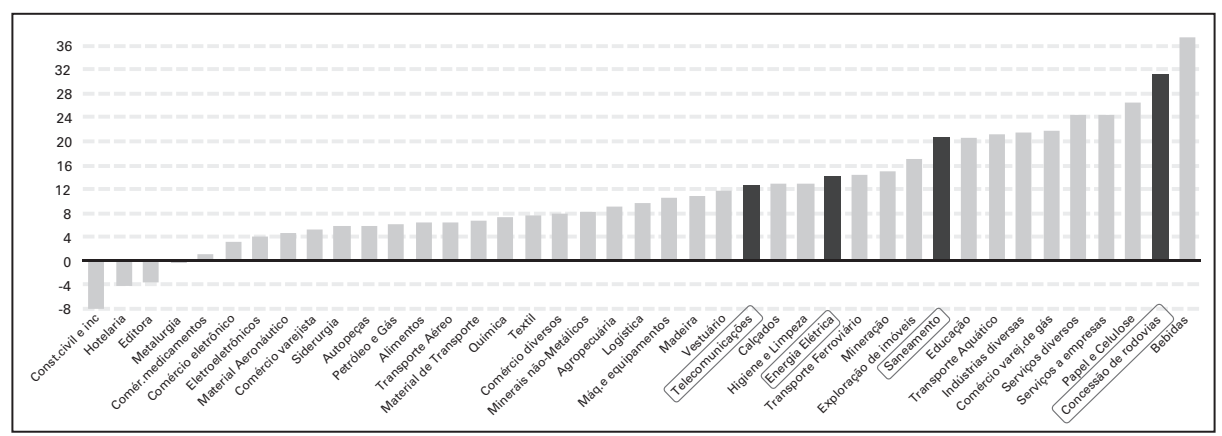

Fonte: Carta IEDI n927. Elaboração própria.

* Relação entre o EBIT (Lucro antes dos Juros e Tributos) e a receita operacional líquida, representa a parcela de lucro antes da incidência de taxas e impostos em cada unidade monetária de receita.

Gráfico 4: Margem Ebitda* por setor, EUA (média 2011-2014) - \%

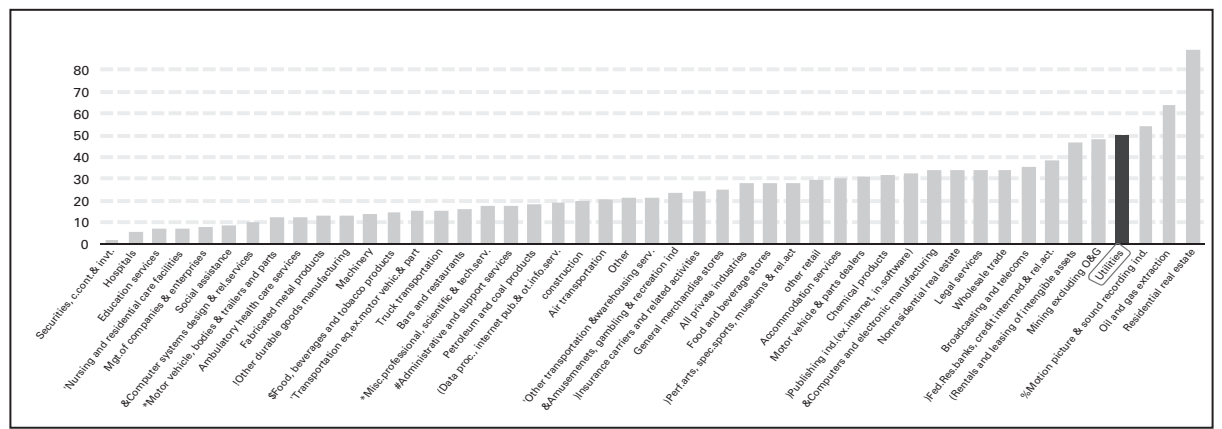

Fonte: Financial Times, Alphaville, com dados do Bureau de Economic Analysis e cálculos de Matthew Klein.

Elaboração própria.

* Relação entre o EBITDA (Lucro antes de Juros, Tributos, Depreciação e Amortização) e a receita operacional líquida. 
Se os lucros têm sido especialmente elevados, o contrário ocorre com a produtividade que, como mostram os Gráficos 5 e 6 para os EUA e a União Europeia, tende a crescer de forma mais lenta neses setores:

Gráfico 5: Crescimento anual da produtividade do trabalho por setor, EUA (média 2000-2018) - \%

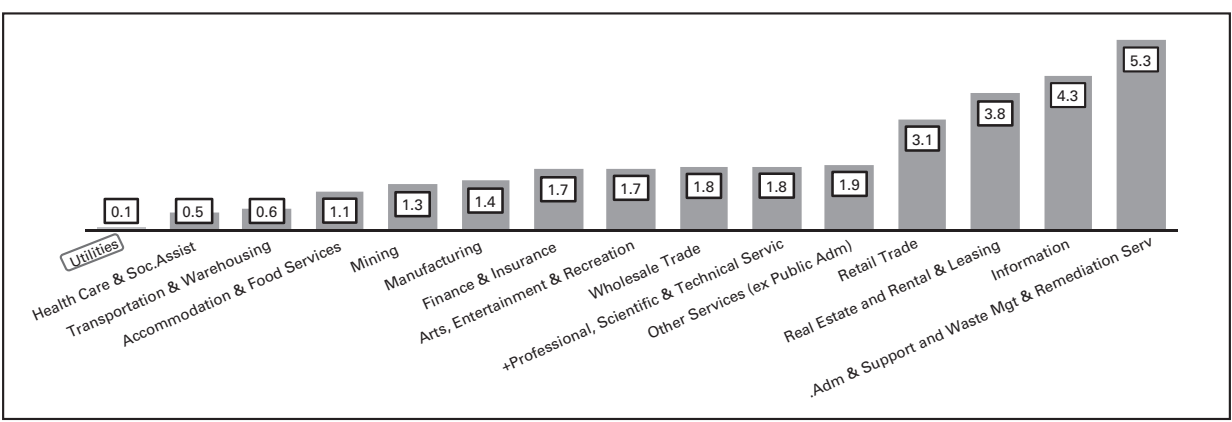

Fonte: US Bureau of Labor Statistics. Elaboração própria.

Gráfico 6: Crescimento anual da produtividade do trabalho por setor, UE (média 2000-2018) - \%

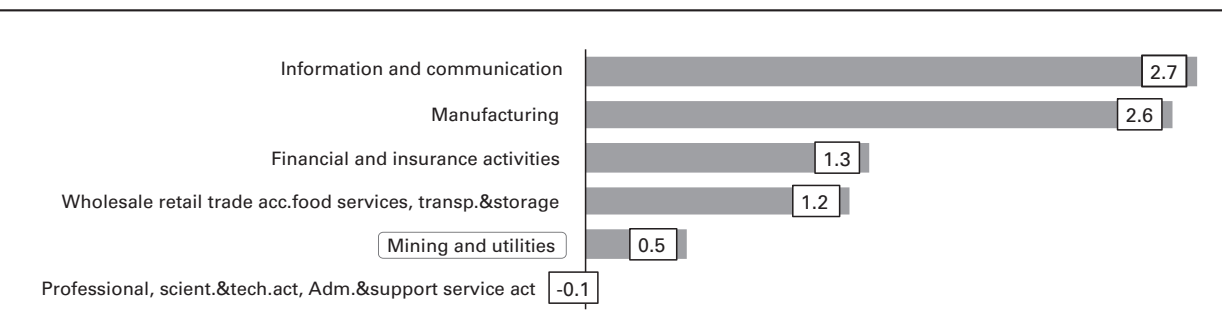

Fonte: OCDE. Elaboração própria.

Lucros extraordinários combinados a aumentos lentos da produtividade como os mostrados nos gráficos são comuns em situações de competição reduzida e regulação ineficaz, características de mercados dominados por monopólios ou oligopólios concentrados, que registram padrões de qualidade inferiores e/ou preços superiores aos que vigorariam em mercados competitivos. Tais preços tendem a ser especialmente elevados nos serviços associados à infraestrutura cuja demanda, ao envolver atividades essenciais, é muito pouco elástica. Os lucros extraordinários frequentemente resultantes dessa situação podem absorver não só a totalidade dos eventuais ganhos de eficiência que a participação privada vier a gerar, como exigir recursos adicionais do governo e usuários. A competição reduzida e a regulação ineficaz tendem ainda a retardar o aumento da produtividade, dado que o risco menor de exclusão do mercado pela concorrência limita a eficácia do mecanismo de seleção das empresas mais eficientes e, dentro de cada empresa, enfraquece a pressão pela incorporação de inovações tecnológicas e gerenciais e pelo aperfeiçoa- 
mento contínuo dos processos. Ainda, a produtividade cresce lentamente porque boa parte dos esforços e capacidades das empresas é dirigida ao desenvolvimento não das expertises técnica e gerencial, que impulsam aquele crescimento, mas de outras como a legal e a de relações governamentais que, se pouco ajudam a elevar a produtividade, são especialmente úteis para sustentar restrições legais e regulamentares a potenciais concorrentes e, com isso, a posição privilegiada da empresa no mercado e sua alta rentabilidade.

\section{COMPETIÇÃO E REGULAÇÃO}

Longe de serem uma curiosidade teórica, a competição reduzida e a regulação ineficaz que propiciam os lucros extraordinários e o avanço lento da produtividade são comuns no setor de infraestrutura em razão dos fatores tratados a seguir.

\section{Competição reduzida}

No setor de infraestrutura são especialmente raras as situações em que a competição, crucial para disciplinar a atuação do parceiro privado, pode se dar no mercado, com vários concorrentes ofertando os serviços e podendo disputar entre $\mathrm{si}^{21}$ como ocorre, por exemplo, na geração de energia elétrica. Normalmente isso não é possível porque a infraestrutura é marcada pela ampla presença de monopólios naturais, caracterizados por elevados custos fixos indivisíveis ligados aos vultosos investimentos não recuperáveis em ativos específicos e às grandes economias de escala e escopo geralmente existentes no setor. Com monopólio natural, a escala mínima de eficiência é grande em relação ao mercado e constitui uma barreira à entrada que inviabiliza a participação de mais de um competidor. ${ }^{22}$ Tipicamente, há monopólio natural na transmissão e distribuição de energia elétrica e de gás, no fornecimento de água e na coleta e tratamento de esgoto, na operação de rodovias, ferrovias e metrôs e outros meios de transporte urbano de massa, e em operações de renovação urbana. Nesses casos, em que a competição no mercado é inviável, ela deve ser buscada na disputa pelo mercado, da qual resulta a escolha do parceiro privado que, geralmente assumindo a forma de uma Sociedade de Propósito Específico - SPE, consórcio de empresas constituído especificamente para esse fim, implantará e administrará a infraestrutura e prestará os serviços públicos dela decorrentes na condição de monopolista sujeito à regulação. Contudo, também a competição pelo mercado é, quando não totalmente ausente, geralmente baixa em

\footnotetext{
${ }^{21}$ Mesmo nos poucos casos na infraestrutura em que a competição no mercado possível, ela não está garantida, já que assim como nos demais setores da economia, também aqui existe a tendência permanente à concentração e à prática de condutas anticoncorrenciais.

${ }^{22}$ A disputa de vários competidores em um mercado caracterizado pelo monopólio natural os obriga a praticar preços inferiores ao custo médio, gerando perdas e levando-os à fusão ou à falência.
} 
razão dos elementos a seguir que, se presentes em todos os mercados, são especialmente relevantes no de infraestrutura, criando barreiras à entrada elevadas que restringem o número de possíveis participantes na disputa e facilitam a colusão.

a) Volume dos investimentos: o elevado volume de investimentos não recuperáveis em ativos específicos dificulta a participação de empresas menores e mais recentes que, dispondo de poucos recursos próprios e menores garantias e histórico reduzido de atividades, são vistas como mais arriscadas por possíveis financiadores (Demirag et al., 2010) e enfrentam maiores dificuldades para obter os recursos requeridos.

b) Complexidade dos projetos: a necessidade de fornecer um conjunto amplo e variado de produtos e serviços exige a integração de múltiplas expertises, detidas por empresas de distintos setores operando em consórcios cuja coordenação requer reputação e capacidade de negociação elevados. A escassez destes atributos, custosos a desenvolver e dominados normalmente por poucos agentes, limita o número de possíveis consórcios.

c) Duração dos contratos: ao se estender com frequência durante décadas e perpassar vários governos de distintas orientações ideológicas, a longa duração aumenta a incompletude dos contratos, já normalmente elevada em razão da complexidade dos projetos. Isso beneficia as empresas maiores e mais longamente estabelecidas, favorecidas nas prováveis disputas com o governo e com outros atores pelo seu relacionamento mais sólido e ramificado nas instituições políticas e judiciais do país, o que afasta novos concorrentes.

d) Incerteza: oriunda dos riscos $i$. não identificáveis (nem todas as variáveis que influenciam o resultado dos projetos são conhecidas), $i i$. não quantificáveis, iii. não gerenciáveis pelas empresas (nem pelo governo), embora frequentemente a elas alocados (como os de demanda, obsolescência tecnológica e climático), e $i v$. financeiramente custosos a gerenciar (como os de taxas de juros e câmbio). A incerteza, muito maior em projetos longos e complexos com compromissos a ser cumpridos por arranjos complexos de agentes com relacionamento futuro em si incerto, favorece as empresas maiores e com maior capacidade de arcar com eventuais perdas ou transferi-las a terceiros.

e) Informação assimétrica: especialmente em projetos complexos, o incumbente detém informações relevantes indisponíveis aos concorrentes e ao governo que lhe dão vantagem na disputa.

f) Custos de licitar: a construção da proposta em projetos complexos exige custos elevados de desenvolvimento e negociação, frequentemente recuperados apenas em caso de lance bem-sucedido, condição que poucos concorrentes podem arcar, o que limita a disputa. Como afirma relatório do Parlamento Britânico: 
"Nós acreditamos que as barreiras à entrada são muito elevadas, resultando em um mercado não competitivo. $\mathrm{O}$ processo longo, complexo e custoso de contratação limita o apetite dos consórcios em participar das licitações, e também significa que somente empresas capazes de arcar com a perda de milhões em lances fracassados podem se envolver". (Parliament, 2011a, par.61).

Quanto maior o volume de investimentos, a complexidade dos projetos, a duração dos contratos, a incerteza, a informação assimétrica, e os custos de licitar, maiores serão as barreiras à entrada e menor tende a ser a competição na disputa pelo mercado. Em projetos de infraestrutura os indicadores de várias ou mesmo todas essas variáveis geralmente assumem valores elevados. Não surpreende que a competitividade nas disputas no setor normalmente seja baixa.

\section{Regulação ineficaz}

A lucratividade e a evolução da produtividade dependem não apenas da existência de disputa no ou pelo mercado, mas também, em especial no segundo caso, da eficácia da regulação, de sua capacidade de desenhar a disputa para que a competitividade seja a maior possível e de monitorar o comportamento do agente privado para que os compromissos quanto à prestação dos serviços, em particular as tarifas e reajustes, os padrões de qualidade e a abrangência do atendimento, sejam respeitados ao longo da execução do contrato. As seguintes razões fazem com que a regulação seja normalmente ineficaz.

a) Captura: o regulador impõe restrições, reduzindo os ganhos potenciais do regulado. Este, frequentemente um ator com grande poder político e econômico, possui assim incentivos claros para oferecer benefícios ao regulador buscando 'capturá-lo' para que a regulação não impacte seus resultados como deveria, mas, ao contrário, contribua para manter ou mesmo elevar seus lucros à custa dos usuários e/ou do governo. Apesar do desenvolvimento de estratégias para reduzi-la (regulação compartilhada, decisões colegiadas, altos salários e quarentena para dirigentes, rotação de funções), a captura (Stigler, 1971) ainda é um problema central da regulação.

b) Informação: grande parte das informações necessárias para que o regulador exerça sua função é produzida pelo regulado, que está geralmente interessado em fornecê-las na menor quantidade e qualidade e com o maior atraso possíveis. Ainda, informações relevantes estão com frequência ocultas sob estruturas corporativas complexas e opacas.

c) Expertise: o regulador geralmente não possui os conhecimentos que somente são adquiridos com a operação prática dos serviços, nem tampouco a expertise técnica atualizada, que evolui rapidamente e apenas é detida por quem exerce continuamente a atividade regulada. 
d) Habilidades negociais: o desenho da contratação desde a fase do pré-projeto, assim como a negociação e administração de contratos marcados por grandes incompletudes, naturais em projetos grandes, complexos e de longa duração, requer aptidões específicas adquiridas na prática comercial que o regulador normalmente não possui. Mesmo no Reino Unido

"A falta de aptidões comerciais comparáveis àquelas do setor privado pode colocar o setor público em desvantagem na negociação e gerenciamento dos contratos. [Apesar dos esforços recentes], as habilidades do setor público não estão tão desenvolvidas quanto as de seus homólogos privados, o que coloca o custo-benefício em risco" (NAO, 2011, p.7).

e) Risco moral: se as hipóteses assumidas no projeto de PPP se mostram conservadoras, os lucros extraordinários são apropriados pelo parceiro privado. Já se o projeto se revela não rentável com a materialização de riscos não gerenciáveis ou mal gerenciados, o parceiro o abandona sofrendo perdas apenas limitadas, as maiores sendo transferidas aos financiadores. O projeto é então encerrado a menos que o governo que, mesmo não explicitamente, é o “detentor residual do risco” (Boardman et al., 2016, p.16) ${ }^{23}$, o assuma ou mude as condições para que outro parceiro privado o faça. A assimetria diante dos riscos, somada à assimetria de informação em favor do parceiro privado derivada de sua experiência em outras parcerias e seu envolvimento nas atividades diárias de gestão do projeto que lhe dão informações que pode usar para transferir ao governo riscos pelos quais é remunerado (Cruz e Da Cruz, 2017), tendem a levá-lo a assumir na disputa pelo mercado um risco socialmente ineficiente.

f) Hold-up: a infraestrutura está normalmente associada a pesados investimentos em ativos específicos que "amarram" a empresa regulada. Esta, por sua vez, ao prestar serviços essenciais para o bem-estar da população e para o funcionamento da economia, e que o governo geralmente não é capaz de assumir ou transferir para outros agentes sem criar perturbações sérias no curto prazo, o "amarram" em relações regidas por leis e contratos complexos e necessariamente incompletos. Isso cria condições para o problema de hold-up em que, para evitar que suas violações contratuais ou regulamentares sejam punidas ou para forçar a renegociação das condições de atuação originalmente estipuladas e torná-las assim mais vantajosas ${ }^{24}$,

\footnotetext{
${ }^{23}$ Comitê do Tesouro do Parlamento Britânico faz a mesma observação:

"O setor público paga pela transferência de risco inerente aos contatos com o parceiro privado, mas o risco em última instância permanece com ele. [...] Isso tem resultado em preços mais altos e se mostrado ineficiente. Algumas das alegadas transferências de risco podem também ser ilusórias - em última instância o governo é o responsável pela entrega dos serviços públicos” (Parliament, 2011a).

${ }^{24}$ Longe de ser excepcional, a renegociação dos contratos de PPPs em infraestrutura é frequente em todo o mundo. Trebilcock e Rosenstock (2015) apontam, por exemplo, que 42\% dos projetos de concessão
} 
um dos parceiros ameaça não cumprir suas obrigações. Na prática, é a posição do governo que tem se revelado relativamente mais frágil, tornando tais "renegociações quase sempre benéficas ao parceiro privado, às custas do público - que admite maiores tarifas ou menores investimentos" (Hall, 2015, p.45).

g) Ineficiência: o regulador é, afinal, um ente público; assim, a baixa eficiência imputada ao governo para prover infraestrutura se aplica ao menos em parte também ao regulador.

Parece pouco crível que um regulador fortemente sujeito ao risco de captura, dependendo em boa medida da informação incompleta, pouco confiável e desatualizada fornecida pelo próprio regulado, dispondo de menor expertise e habilidades negociais em relação a seus homólogos privados, enfrentando os comportamentos oportunistas associados ao risco moral e ao hold-up e, ainda, atuando de acordo a procedimentos próprios ao setor público, seja capaz de regular eficazmente um setor operado por agentes privados que frequentemente possuem elevado poder político e econômico.

\section{AUMENTO DE CUSTOS}

A competição reduzida e a regulação ineficaz que tendem a elevar os lucros e desacelerar os ganhos de produtividade na infraestrutura reduzem a probabilidade de que a participação privada de fato melhore o custo-benefício da contratação. Este cai ainda quando consideramos alguns custos que tendem a ser maiores no setor privado.

O mais citado é o custo de capital, que geralmente representa parcela relevante dos custos totais dos projetos de infraestrutura, tanto maior quanto maior forem a taxa de juros, a parcela dos investimentos em relação ao total dos contratos, e a duração destes. Dado que a infraestrutura com frequência requer vultosos investimentos apenas amortizados após longos períodos, pequenas diferenças nas taxas provocam grandes variações nos custos. E, como o Estado desfruta em geral das melhores condições de financiamento dentro de sua jurisdição, a provisão privada normalmente implica custos maiores.

Com efeito, relatório recente do NAO para o Reino Unido apontou que nos projetos iniciados desde 2013 o custo de capital dos investidores privados em infraestrutura foi de $2 \%$ a $4 \%$ maior que o do governo, chegando a mais de $5 \%$ em

firmados na América Latina e Caribe entre 1985 e 2000 foram renegociados, 2/3 sob demanda da empresa, em geral favorecendo o operador. Já Hall (2015) indica que $33 \%$ dos projetos de PPP firmados no Reino Unido entre 2004 e 2006 foram renegociados. A despeito do aperfeiçoamento constante das licitações e contratos, o fenômeno continua a ocorrer: de 146 projetos analisados iniciados em todo o mundo entre 2005 e 2015, 20\% havia passado por uma renegociação nos primeiros quatro anos após a assinatura, e $50 \%$ daqueles que já duravam onze anos (GIH, 2018). 
alguns contratos (NAO, 2018, p.14). Em um período em que a remuneração dos títulos de 10 anos geralmente esteve abaixo dos $2 \%$, isso significa que o custo de capital privado foi o dobro ou mesmo mais. Spreads parecidos, entre 2\% e 2,5\% e chegando a 4\% em 2009 se verificaram, por exemplo, também no Canadá (Ford, 2013). No Brasil, no início de 2019, o custo de capital mais baixo para o setor privado, aquele pago pelas debêntures de infraestrutura, se situava entre $0,3 \%$ e $2 \%$ acima das taxas cobradas do governo em condições comparáveis (ME, 2019).

Os custos de transação, por sua vez, necessários para negociar, redigir e garantir o cumprimento dos contratos, também tendem a ser maiores no caso das PPPs. Esses custos notadamente incluem, por parte do governo, os custos de regulação, aqueles exigidos para desenhar a parceria, selecionar o parceiro privado e gerir uma relação complexa com interesses frequentemente conflitantes ao longo da duração do contrato. Isso envolve coletar e analisar dados e monitorar o desempenho, aplicar sanções, resolver disputas e eventualmente renegociar as condições, o que requer uma custosa estrutura regulatória capaz de executar essas funções. Já o parceiro privado incorre em custos de negociação com fornecedores para estruturar o consórcio e preparar a proposta e com financiadores para garantir os recursos requeridos, e de gerenciamento dos interesses conflitantes dentro da SPE e da relação com sucessivos governos. Os custos assumem a forma de recursos humanos, tecnológicos e outros alocados no governo e nas empresas e, em razão da complexidade dos projetos e da carência por parte desses atores de habilidades específicas requeridas, da ampla contratação de consultorias externas. Os consultores estão presentes em todas as fases do processo, desde mesmo antes da escolha do modelo de parceria até seu encerramento, passando pela preparação das propostas, negociação, redação e monitoramento do contrato e renegociação e resolução de litígios. Atuam nas áreas técnicas, legal, contábil e financeira, de tributação e seguros, e na própria estruturação das $\mathrm{PPPs}^{25}$. O segmento de consultoria especializada no arranjo cresceu fortemente nas últimas décadas e, inclusive, hoje constitui um grupo de pressão relevante.

A magnitude dos custos de transação depende do grau de especificidade dos ativos, que dificulta a substituição dos agentes mesmo quando comportamentos oportunistas são identificados, da complexidade dos produtos e serviços, e da incerteza envolvida, que aumentam a incompletude dos contratos e favorecem aqueles comportamentos (Williamson, 1981). As três variáveis tendem a assumir, no caso de contratos de PPPs, valores elevados. Com isso, estes geralmente apresentam maiores incompletudes que na contratação tradicional, e a solução das disputas que delas derivam ao longo do tempo tende a gerar custos de transação também maiores. Esses custos crescem ainda com a baixa contestabilidade do mercado e a

\footnotetext{
${ }^{25}$ Particularmente expressivos devido à sua estruturação financeira em geral complexa, envolvendo variados instrumentos e atores, são as taxas e honorários pagos a bancos, agências de rating, corretores e outros que, no Reino Unido, atingem tipicamente $1 \%$ dos valores emprestados, podendo chegar a $2 \%$ (NAO, 2018, p.15).
} 
limitada capacidade do regulador em gerenciar o contrato, que são comuns em PPPs e elevam a probabilidade de comportamento oportunista (Vining et al., 2005). Evidências dos altos custos de transação nas PPP aparecem, por exemplo, em estudo para o Reino Unido apontando que, apenas na fase de contratação ${ }^{26}$ o que exclui os custos de monitoramento e renegociação na fase operacional -, eles equivalem a mais de $10 \%$ do valor do projeto (Dudkin e Valila, 2005). Em comparação, extenso estudo encomendado pela Comissão Europeia (PWC, 2011) mostra que os custos de transação na contratação tradicional se situam em patamares muito menores, em torno de $1,4 \%$ do valor das compras, embora o percentual tenda a crescer nas contratações de menor valor.

Além dos custos de capital e de transação, outros custos tendem a ser maiores em PPPs como é o caso dos seguros. Isto porque enquanto para o governo, organização normalmente maior e mais diversificada que qualquer outra dentro do país, faz sentido se autoassegurar contra riscos não gerenciáveis, o setor privado deve contratar esse seguro junto a terceiros. Com contratos longos e pouco flexíveis, também o custo de alterar características dos produtos e serviços fornecidos ou mesmo interromper o fornecimento em razão de mudanças culturais, políticas, ambientais, tecnológicas e outras, prováveis em intervalos de tempo prolongados, se torna elevado, quando não proibitivo, chegando a levar o governo a continuar pagando por itens que não mais precisa. Além de custosas, tais mudanças, devendo ser normalmente submetidas a estruturas de governança complexas dentro das SPEs, se tornam demoradas, eventualmente gerando custos adicionais. Ainda, a variedade de atores com interesses por vezes conflitantes provendo os produtos e serviços no âmbito da SPE dificulta o planejamento e a obtenção de sinergias e reduz a qualidade da informação que chega a suas instâncias decisórias superiores, elevando os custos da operação. Finalmente, a complexidade própria aos arranjos de PPP, a dispersão de informação por trás de estruturas corporativas complexas e opacas e a pouca informação sobre partes relacionadas dificultam a partilha dos ganhos de eficiência e colocam obstáculos a iniciativas do governo em busca de economias, uma vez que seu relacionamento com o provedor do bem ou serviço alvo é intermediado pela estrutura burocrática, em especial legal e de relações públicas, da SPE.

\section{ENTUSIASMO JUSTIFICÁVEL?}

Vimos em seções anteriores que, com a competição reduzida e as dificuldades da regulação, os lucros das empresas na infraestrutura tendem a ser elevados e sua produtividade a crescer lentamente. Vimos também que certos custos relevantes

\footnotetext{
${ }^{26}$ As PPPs normalmente carregam importantes custos de monitoramento e de enforcement do contrato. Torres e Pina (2001) trazem evidências dos EUA sugerindo que essas atividades numa PPP geram custos de entre $3 \%$ e $25 \%$ do valor do projeto, que se somam àqueles incorridos na contratação.
} 
são geralmente maiores no setor privado. Ambos os pontos reduzem a probabilidade de que o custo-benefício da provisão privada de infraestrutura seja melhor que o da provisão direta pelo governo, especialmente em projetos complexos, de longa duração e que requeiram grandes investimentos. Logo, conclusões como a de Hellowell (2010, p.329) sobre a experiência do Reino Unido alinhadas à posição de comitês do Parlamento Britânico que igualmente se debruçaram sobre o tema (Parliament, 2011a e 2014) não devem surpreender:

"[...] a evidência sugere que o programa de PPPs não proporciona vantagens claras em termos de construção, manutenção ou serviços mais eficientes. Até o momento, a vantagem do setor privado em melhorar a entrega de projetos de infraestrutura pública [...] não foi demonstrada - na verdade, a evidência disponível, que não deve ser vista como conclusiva, sugere que, de modo geral, as PPPs estão associadas a entregas com custos maiores".

Isso não significa que todo e qualquer projeto envolvendo a provisão privada de infraestrutura necessariamente apresentará resultados frustrantes, com pior custo-benefício que o da provisão pública direta. Em particular no caso dos governos subnacionais, a possibilidade de prover diretamente a infraestrutura pode simplesmente não existir em razão da falta de recursos nas mãos do governo, da impossibilidade legal de tomar empréstimos ou de seu custo proibitivo. Nessas situações, o recurso ao setor privado, não obstante os problemas aqui discutidos, pode vir a mostrar-se a melhor quando não a única maneira de contornar tais limitações e permitir que o projeto seja de fato executado. Também em projetos pouco complexos, de curta duração, com baixa incerteza e que não envolvam grandes investimentos, onde os problemas aqui indicados são menores, a participação privada na provisão de infraestrutura pode apresentar resultados positivos. Ou seja, certamente há situações em que essa participação pode se mostrar conveniente. Todavia, seu número é muito menor que o destaque dado no debate público a posições favoráveis ou mesmo entusiasmadas de analistas no governo e no setor privado no Brasil e no exterior levam a crer.

Esses analistas têm apontado a provisão privada como a melhor solução para projetos de infraestrutura em praticamente qualquer situação, e como instrumento decisivo para promover sua transformação no país. Ao defender os esforços para expandi-la e mesmo generalizá-la, subestimando ou mesmo ignorando as objeções teóricas aqui discutidas, assim como a falta de evidências empíricas robustas a apoiá-la, eles implicitamente abraçam duas hipóteses cruciais altamente questionáveis. A primeira assume que o mesmo governo que, nessa visão, é totalmente incapaz de prover diretamente a infraestrutura e os serviços dela decorrentes de forma satisfatória, seria capaz de promover a competição no ou pelo mercado e de regular adequadamente, inclusive impondo obrigações e penalidades, a ação de atores política e economicamente poderosos com interesses em grande parte antagônicos ao interesse público. Ainda, seria capaz de fazer isso apesar de dispor de menos 
informação, expertise e habilidades do que o regulado. Tal hipótese duvidosa é absolutamente central pois, caso não seja satisfeita, a competição reduzida e a regulação ineficaz tendem a elevar excessivamente as tarifas cobradas dos usuários e/ou do governo e a reduzir a qualidade dos serviços, alimentando os lucros do parceiro privado à custa da sociedade, com efeitos distributivos perversos em razão da participação relativamente mais alta dos gastos com esses serviços na renda dos mais pobres.

A segunda hipótese duvidosa, mas igualmente central, é a de que enquanto os esforços de transformação institucional buscando possibilitar a provisão eficaz e eficiente de infraestrutura pelo governo estão fadados ao fracasso, aqueles empreendidos para viabilizar a provisão privada devem persistir até alcançarem seus objetivos. O domínio dessa visão ajuda a explicar casos como o brasileiro, marcado pelo contraste entre, por um lado, o alto número de mudanças legais, a manutenção de uma pesada estrutura regulatória, e o entusiasmo no discurso oficial quanto à atuação privada na infraestrutura, e, pelo outro, iniciativas apenas muito tímidas para aumentar a qualidade da provisão pública direta.

A preferência ideológica da maioria dos analistas do tema que insiste em impor à realidade a presença de estruturas de mercado competitivas quando elas estão claramente ausentes é essencial para a aceitação dessas hipóteses. Certamente, os crescentes interesses econômicos criados em torno da participação privada em infraestrutura contribuem decisivamente para sustentá-la. Enquanto ela permanecer majoritária, o entusiasmo com essa participação, mesmo que infundado teórica e empiricamente, deve continuar.

\section{REFERÊNCIAS BIBLIOGRÁFICAS}

Abadie, R. (2008) “Infrastructure finance - surviving the credit crunch", Talking Points, Public Sector Research Centre-PricewaterhouseCoopers.

AbconSindcon (2018) "Panorama da participação privada no saneamento 2018”, Associação Brasileira das Concessionárias Privadas de Serviços Públicos de Água e Esgoto e Sindicato Nacional das Concessionárias Privadas de Serviços Públicos de Água e Esgoto.

Alexandersson, G.; Hulten, S. (2009) "Prospects and pitfalls of public-private partnerships in railway transportation: Theoretical issues and empirical experience", International Journal of Transport Economics, 36, 97-119.

Araújo, S.; Sutherland, D. (2010) "Public-Private Partnerships and Investment in Infrastructure", OECD Economics Department Working Papers No.803.

Bayliss, K.; Van Waeyenberge, E. (2018) “Unpacking the Public Private Partnership Revival”, The Journal of Development Studies, Volume 54, Issue 4.

Boardman, A. E.; Vining, A. R. (2010) "Assessing the economic worth of public-private partnerships". In Hodge, G.A.; Greve, C.; Boardman, A.E. (eds), International Handbook on Public-Private Partnerships. Cheltenham, UK: Edward Elgar, 159-186.

Boardman, A.E.; Siemiatycki, M.; Vining, A.R. (2016) "The theory and evidence concerning public-private partnerships in Canada and elsewhere”, SSP Research Papers, Volume 9, Issue 12, March.

Boers, I.; Hoek, F.; van Montford, C.; Wieles, J. (2013) "Public-private partnerships: International audit findings". In de Vries, P.; Yehoue, E.B. (eds) The Routledge companion to public-private partnerships (451-478). Abingdon, UK: Routledge. 
Burger, P; Tyson, J.; Karpowicz, I.; Coelho, M.D. (2009) "The effects of the financial crisis on Public-Private Partnerships”, International Monetary Fund Working Paper WP/09/144, International Monetary Fund, Washington, DC.

ME (2019) "Boletim Informativo de Debêntures Incentivadas", Ministério da Economia, $68^{\circ}$ ed, julho.

Chong, E.; Huet, F.; Saussier, S.; Steiner, F. (2006) "Public-Private Partnerships and Prices: Evidence from Water Distribution in France”, Review of Industrial Organization, 29:149-169.

CNI (2017) “Oportunidades para a privatização da infraestrutura: O que fazer, como fazer”. Brasília: CNI.

Cruz, C.O.; Da Cruz, N.F. (2017) "Public-private partnership: a framework for private sector involvement in public infrastructure projects", LSE Research Online, March.

Dee, P. (2010) "Quantifying the Benefits from Structural Reforms in Electricity and Gas Markets in APEC Economies". Contribution to the project 'The Impacts and Benefits of Structural Reforms in Transport, Energy and Telecommunications Sectors', commissioned by the APEC Policy Support Unit.

Demirag, I.S.; Khadaroo, I.; Stapleton, P.; Brown (Stevenson), C. (2010) "Public private partnership financiers' perceptions of risks", The Institute of Chartered Accountants of Scotland, Edinburgh.

Dudkin G.; Välilä T. (2005) "Transaction Costs In Public-Private Partnerships: A First Look At The Evidence", EIB Economic and Financial Report 2005/03.

ECA (2018) "Public Private Partnerships in the EU: Widespread shortcomings and limited benefits", Special Report $\mathrm{n}^{\circ}$, European Court of Auditors.

Elliot, M; Kanagasooriam, J. (2017) "Public opinion in the post-Brexit era: Economic attitudes in modern Britain”, Legatum Institute.

Ettinger, S.; Schur, M.; von Klaudy, S.; Dellacha, G.; Hahn, S. (2005) "Developing Country Investors and Operators in Infrastructure", Trends and Policy Options $N^{\circ} 3$. Washington: Public-Private Infrastructure Advisory Facility.

Fiorio, C.V.; Florio, M. (2013) "Electricity prices and public ownership: Evidence from the EU15 over thirty years," Energy Economics, Elsevier, vol. 39(C), pages 222-232.

Flinders, M. (2010) "Splintered Logic and Political Debate” In Hodge, G.A.; Greve, C.; Boardman, A.E. (eds) International Handbook on Public-Private Partnerships. Cheltenham: Edward Elgar, pp. $115-31$

Ford, D.A. (2013) “The role of capital markets in P3 financing”, Torys Capital Markets Mid-Year Report.

Frischtak, C.R.; Mourão, J. (2018) “Uma estimativa do estoque de capital de infraestrutura no Brasil" In De Negri, J.A.; Araújo, B.C.; Bacelette, R. (orgs) Desafios da Nação: artigos de apoio, volume 1. Ipea, Brasília.

GIH (2018) “Managing PPP Contracts After Financial Close”, Global Infrastructure Hub.

Hellowell, M. (2010) “The UK's Private Finance Initiative: history, evaluation, prospects”. In Hodge, G.A.; Greve, C.; Boardman, A.E. (eds) International Handbook on Public-Private Partnerships. Cheltenham, UK: Edward Elgar, 307-332.

Hodge, G. A. (2010) “Reviewing public-private partnerships: Some thoughts on evaluation”. In Hodge, G.A.; Greve, C.; Boardman, A.E. (eds) International Handbook on Public-Private Partnerships. Cheltenham, UK: Edward Elgar, 81-112.

Hodge, G. A., \& Greve, C. (2007) "Public-private partnerships: An international review", Public Administration Review, 67, 545-558.

Hodge, G.A.; Greve, C. (2017) “On Public-Private Partnership Performance: A Contemporary Review”, Public Works Management \& Policy, Vol. 22(1) 55-78.

IMF (2015) "Making public investment more efficient", Staff Report. International Monetary Fund Washington, D.C., June.

Jin, H.; Rial, I. (2016) "Regulating Local Government Financing Vehicles and Public-Private Partnerships in China”, IMF Working Paper WP/16/187.

Kishimoto, S.; Steinfort, L; Petitjean, O. (2019) "The Future is Public: Towards democratic ownership of public services", Transnational Institute. 
Labour (2018) "Clear Water: Labour's vision for a modern and transparent publicly-owned water system". Labour Party, London.

NAO (2009). "Private finance projects". A Paper for the Lords Economic Affairs Committee. National Audit Office, London, England: The Stationery Office.

NAO (2011). "Lessons from PFI and other projects". Report by the Comptroller and Auditor General. National Audit Office, London, England: The Stationery Office.

NAO (2013). "Review of the VFM assessment process for PFI". Briefing for the House of Commons Treasury Select Committee. National Audit Office, London, England: The Stationery Office.

NAO (2018). "PFI and PF2". Report by the Comptroller and Auditor General. National Audit Office, London, England: The Stationery Office.

OECD (2012) "Recommendation of the Council on Principles for Public Governance of Public-Private Partnerships", May.

Parliament (2011a) "Private Finance Initiative”, Proceedings of the Treasury Committee, $17^{\circ}$ Report of Session 2010-12, House of Commons.

Parliament (2011b) "Lessons from PFI and other projects", Proceedings of the Public Accounts Committee, $44^{\circ}$ Report of Session 2010-12, House of Commons.

Parliament (2014) “Private Finance 2", Proceedings of the Treasury Committee, $10^{\circ}$ Report of Session 2013-14, House of Commons.

Pollock, A.; Price, D.; Playe, S. (2007) “An examination of the UK treasury's evidence base for cost and time overrun data in UK value-for-money policy and appraisal”, Public Money \& Management, 27, 127-134.

PWC (2011) "Public procurement in Europe Cost and effectiveness", PricewaterhouseCoopers. A Study on Procurement Regulation Prepared for the European Commission.

Shaoul, J.; Stafford, A.; Stapleton, P. (2012) "The fantasy world of private finance for transport via public private partnerships", International Transport Forum. OECD, Paris.

Stigler, G.J. (1971) "The theory of economic regulation", The Bell Journal of Economics and Management Science, Vol. 2, No. 1 (Spring, 1971), pp. 3-21.

TCU (2019) “Relatório de auditoria”, Acórdão 2190/2019, Tribunal de Contas da União.

Torres, L.; Pina, V. (2001). "Public-private partnership and private finance initiatives in the EU and Spanish local governments”. The European Accounting Review, (10:3), pp. 601-619.

Trebilcock, M.; Rosenstock, M. (2015) "Infrastructure PPPs in the developing world: lessons from recent experience”, The Journal of Development Studies, 51:4, 335-354.

Vining, A.R; Boardman, A.E.; Poschmann, F. (2005) "Public-private partnerships in the US and Canada: 'There are no free lunches'”, Journal of Comparative Policy Analysis, Volume 7, Issue 3.

Williamson, O.E. (1981) "The Economics of Organization: The Transaction Cost Approach," The American Journal of Sociology, 87, 3: 548-577.

World Bank (1994) “World Development Report 1994: Infrastructure for Development”. New York: Oxford University Press.

World Bank (2003) "Implementing the World Bank Group Infrastructure Action Plan". September 12th.

World Bank (2011) “Transformation through Infrastructure”. Washington D.C.: The World Bank.

World Bank (2013) "World Bank Group Strategy". Washington, DC: World Bank Group.

World Bank (2018) "Procuring Infrastructure Public-Private Partnerships". Washington D.C.: The World Bank. 